\title{
Artery of Percheron Occlusion: A Diagnostic Challenge
}

\author{
Carina Ramalho, Mariana Almeida, Francisco Gomes, Magda Silva, Joaquim Peixoto, Silvia Rodrigues \\ Centro Hospitalar Barreiro Montijo, Barreiro, Portugal
}

Doi: 10.12890/2021_003020 - European Journal of Case Reports in Internal Medicine - ๑ EFIM 2021

Received: 21/10/2021

Accepted: 30/10/2021

Published: 17/11/2021

How to cite this article: Ramalho C, Almeida M, Gomes F, Silva M, Peixoto J, Rodrigues S. Artery of Percheron occlusion: a diagnostic challenge. EJCRIM 2021;8: doi:10.12890/2021_003020.

Conflicts of Interests: The authors declare there are no competing interests.

This article is licensed under a Commons Attribution Non-Commercial 4.0 License

ABSTRACT

Artery of Percheron occlusion is a rare cause of ischaemic stroke characterized by bilateral thalamus infarction. Presentation is varied and non-specific, with the most frequent manifestations being altered level of consciousness, hypersomnolence or altered oculomotor movements. We describe the case of a 37-year-old man hospitalized for hypersomnia and hypomnesia with 3 days of evolution, who was diagnosed with a bilateral thalamus stroke due to artery of Percheron occlusion.

\section{LEARNING POINTS}

- Stroke is frequently encountered but can present a diagnostic challenge when presentation is non-specific or a lesion is not identified.

- Artery of Percheron stenosis has a varied and often non-specific presentation, which can lead to delayed diagnosis and treatment of these patients.

- It is important that doctors recognize this entity for timely diagnosis and treatment, and for the best prognosis.

\section{KEYWORDS}

Artery of Percheron, cerebral infarction, hypersomnia, thalamus

\section{CASE DESCRIPTION}

A 37-year-old leucodermic fisherman, with a history of tobacco and hashish use since 20 years of age was admitted to the emergency department because of hypersomnia, with periods of sleep longer than 24 hours, and hypomnesia with 3 days of evolution. The physical and neurological examinations were normal. A brain CT scan was performed and showed bi-thalamo-mesencephalic hypodensities, which were relatively symmetrical and suggestive of acute ischaemic lesions in artery of Percheron territory (Fig. 1).

The patient was admitted for aetiological study of the stroke. No abnormalities were seen on electrocardiogram or transthoracic echocardiogram, while investigations for thrombophilia, autoimmunity and viral infection were negative. An MRI scan showed symmetrical, circumscribed bilateral thalamic lesions with a T2 hypersignal, with no restriction of proton diffusion. There was an incipient mass effect on the third ventricle, which was partially obliterated. The lesions were likely ischaemic in nature, late subacute, and probably due to infarction of the artery of Percheron. These findings confirmed the diagnosis.

The patient was prescribed $100 \mathrm{mg}$ acetylsalicylic acid daily and statin, and discharged without neurological deficits. He was referred for an Internal Medicine consultation to continue the aetiological investigation but did not attend. 


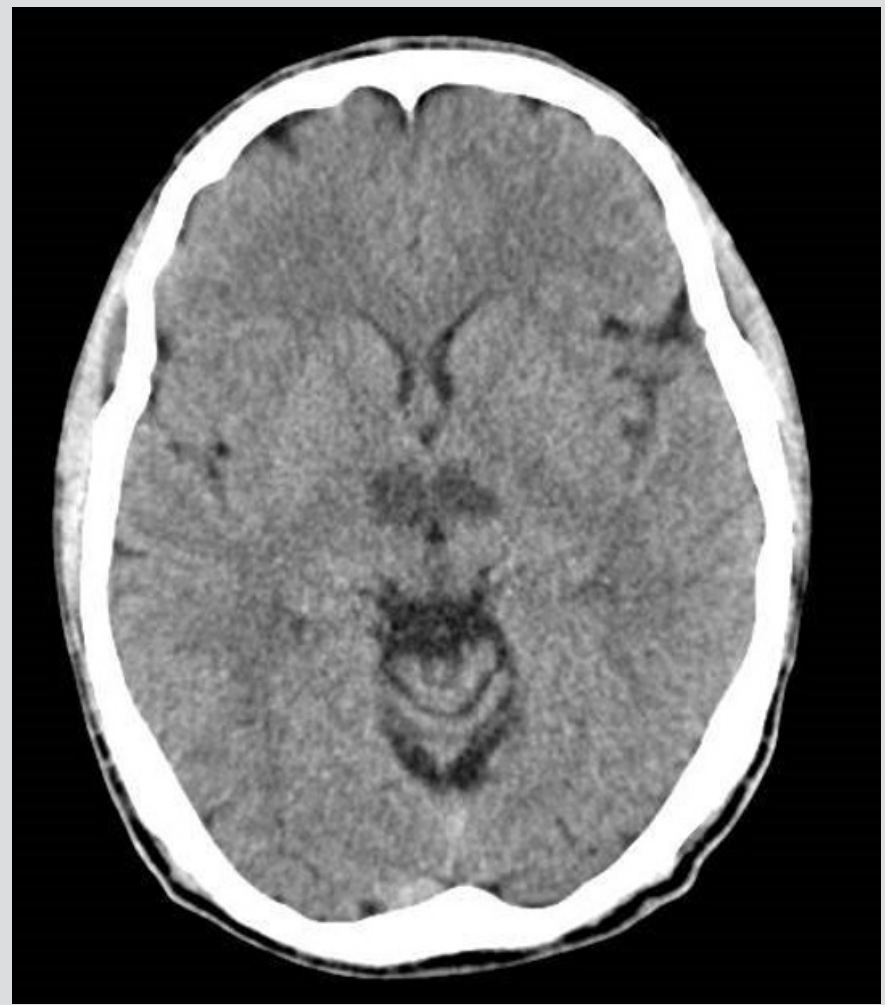

Figure 1. Brain computed tomography showing hypodensity in the medial thalamus bilaterally

\section{DISCUSSION}

The artery of Percheron is one of four anatomical variants of the paramedian artery, in which a single arterial trunk emerges from one of the posterior cerebral arteries to irrigate the paramedian region of the thalamus and the midbrain on both sides of the brain. These structures help regulate consciousness, sleep and awakening, and ischaemia in this region can manifest in various forms, such as changes in the state of consciousness or memory, psychosis, aphasia, dysarthria or oculomotor dysfunction ${ }^{[1-3]}$. This variant is estimated to occur in $33 \%{ }^{[4]}$ of the population and infarctions of this artery represent $4-18 \%$ of all thalamic infarcts and $0.1-2 \%{ }^{[5]}$ of all strokes.

The variations in thalamic vascular anatomy together with the wide range of functions that this structure performs explain the variety of symptoms associated with thalamic infarctions and, consequently, the diagnostic challenge they represent. This has consequences for the treatment and prognosis of patients, so a high level of suspicion should be maintained, especially in patients with sensory changes and vague neurological signs that are not particularly disease specific.

In this case, the rarity and low specificity of the presenting symptoms led to a delay in the patient accessing health care. Nevertheless, the patient was quickly diagnosed and treatment initiated. During hospitalization, no aetiology for stroke was identified, but the consumption of tobacco and hashish for several years may have been a predisposing factor.

\section{REFERENCES}

1. Khanni JL, Casale JA, Koek AY, Espinosa del Pozo PH, Espinosa PS. Artery of Percheron infarct: an acute diagnostic challenge with a spectrum of clinical presentations. Cureus 2018;10(9):e3276.

2. Goico A, Mikesell T. Artery of Percheron infarction: a rare cause of somnolence in a patient with sepsis and atrial fibrillation. Oxf Med Case Rep 2018;2018(7):204-205.

3. Snyder HE, Ali S, Sue J, Unsal A, Fong C, Deng Z. Artery of Percheron infarction with persistent amnesia: a case report of bilateral paramedian thalamic syndrome. BMC Neurol 2020;20(1):1-6.

4. Sasi S, Ahmed A, Yousuf W, Vattoth S. Artery of Percheron infarct: a rare presentation of acute ischemic stroke in a high-risk antiphospholipid syndrome patient. Case Rep Acute Med 2020;3(2):46-52.

5. Kichloo A, Jamal SM, Zain EA, Wani F, Vipparala N. Artery of Percheron infarction: a short review. J Investig Med High Impact Case Rep 2019;7:0-5. 